\title{
CONTRIBUIÇÕES POSSÍVEIS DE PIERRE HADOT AO ENSINO DE FILOSOFIA
}

\author{
Gabriel Rodrigues Rocha ${ }^{1}$
}

RESUMO: O artigo propõe demonstrar o quanto é possível pensar o ensino de filosofia como problema filosófico. A partir da utilização de conceitos cruciais que, embora não fossem pensados em sua originalidade na relação com ensino de filosofia, possibilitaram desenvolver e reflexionar sobre novas perspectivas para problematizar a questão fundamental do ensinar e aprender filosofia nas salas de aula. Os estudos de Pierre Hadot sobre filosofia antiga fundamentam-se em dois princípios fundamentais: "a filosofia como modo de vida" e "exercícios espirituais". Neste viés interpretativo utilizou-se lhe de tais conceitos ou princípios, aos quais fundamentam o caráter comum da filosofia antiga, ao longo dos séculos que a cobrem, para se lhe utilizarem como possível caminho interpretativo às questões que envolvem o ensino e o aprendizado de filosofia. Neste propósito, contribuiu-se a esta elaboração hermenêutica, servindose de alguns postulados sugeridos pela filósofa e Madre, Montserrat del Ponzo.

PALAVRAS-CHAVE: Ensino; Exercícios Espirituais; Filosofia; Modo de Vida. 
ABSTRACT: The article aims to show how it is possible to think the teaching of philosophy as a philosophical problem. From the use of key concepts that, although they were not thought in its originality in relation to teaching philosophy, made it possible to develop and reflect on new perspectives to discuss the fundamental question of philosophy teaching and learning in classrooms. Pierre Hadot studies on ancient philosophy are based on two fundamental principles: "the philosophy and way of life" and "spiritual exercises". In this interpretive bias we used him such concepts or principles which underlie the common character of the ancient philosophy, over the centuries that cover, to use him as a possible interpretative path to issues involving teaching and philosophy Learning . In this way, contributed to this hermeneutic preparation, serving up some postulates suggested by philosopher and Mother, Montserrat del Ponzo.

KEYWORDS: Lifestyle; Philosophy; Spiritual Exercises; Teaching. 


\section{ENSINO DE FILOSOFIA E A FILOSOFIA COMO MODO DE VIDA}

Embora a temática de ensino de filosofia seja ampla, isto é, passível a diferentes formas de análise e compreensão, bem como, submetida a múltiplos e, por vezes, antagônicas posições teórico-práticas quanto a investigação do tema, considera-se que o ensino de filosofia é área fundamental aos estudos e a pesquisa em filosofia.

Crê-se que, desde a originalidade filosófica grega, a filosofia (philosophía) como saber específico que a constitui mediante problematizações que lhe são características, aproxima-se do que poder-se-ia considerar de ensino filosófico. Isto é, o ser filósofo é sempre equivalência de ser educador, no sentido de que o filósofo sempre propôs em suas questões, novas formas de análise e compreensão do que compõe o mundo e o homem.

Entrementes, é sobretudo a partir do filósofo Sócrates e de seu principal discípulo, Platão, que o homem tornado objeto de análise e de investigação filosófica que a filosofia se tornará o saber fundamental à educação (paideía) do homem. Mas, diferentemente de nossa contemporaneidade a educação relacionava-se mais com a formação do caráter e dos caracteres que formam a conduta humana, do que simplesmente com a instrução intelectual.

Conforme Jaeger (2003, p.7): “A ideia de educação representava para ele [o Homem grego] o sentido de todo o esforço humano. Era a justificação última da comunidade e individualidade humanas". 
Neste sentido a propósito da ponderação de Jaeger, encontra-se em Platão e Aristóteles, assim como nas filosofias helenísticas e do período imperial romano, a filosofia como o saber que objetiva formar individualidades a partir de princípios éticos de virtude, em que o aprimoramento intelectual jamais encontra-se desvinculado dos problemas que perpassam a vida prática. Assim, o sentido ou a teleologia do saber filosófico é a ação humana².

Para Pierre Hadot (2009, p.39-14), em sua proposta interpretativa da filosofia antiga, assere que esta "seria possuidora de duas dimensões discursivas, aquela que propõe ensinar uma doutrina, ensinar a raciocinar e, outra mais profunda, que busca uma 'transformação de si'".

Quer-se demonstrar que é possível utilizar-se destas duas dimensões discursivas que comporiam a filosofia antiga, para então, pensa-la como metodologia possível e, contribuidora ao ensino de filosofia.

A dimensão que se propõe ao ensino, diga-se, ao ensino formal e teórico, abrange ou deveria abranger, qualquer prática docente em filosofia, seja em viés mais profundamente temático ou de cunho mais histórico. Assim, os temas e os problemas filosóficos em seus respectivos conceitos formulados ao longo de uma tradição, remonta a séculos de história do pensamento, e são objetos de leitura e interpretação, de análise e escrita, de resumos e exercícios, comumente a comporem o trabalho filosófico em salas de aula.

Do que se segue que a prática filosófica compreendida como ensino e como aprendizagem, desenvolvem habilidades específicas, tais como, a interpretação e compreensão textual, 
a abstração discursiva, o raciocínio lógico, a oralização, a sensibilidade estética e moral, a criticidade política e a cidadania, bem como a quaisquer produções escritas e orais que visem a exposição coerente de argumentos que se quer apresentar, desenvolver e concluir de forma exitosa ${ }^{3}$.

A inovação, na possibilidade hipotética de contribuir com o ensino de filosofia, encontra-se, como referendado, ao que Hadot caracteriza como a "segunda dimensão discursiva" da filosofia antiga, isto é, a dimensão que promoveria uma "transformação de si". Mas antes de se tratar do discurso, primeiramente pergunta-se: $O$ que significa esta transformação de si? Para o êxito compreensivo a este questionamento, ora primordial a proposta deste artigo, deve-se ponderar sobre o que significa a proposição: a filosofia como modo de vida.

Conceito fundamental em Hadot, a filosofia como modo de vida é o elemento comum e primordial, característico à filosofia na Antiguidade. Portanto, embora houvessem diferentes escolas filosóficas, dentro deste período históricofilosófico do que se denomina filosofia antiga, cada qual com as suas especificidades, o modo de vida seria, segundo Hadot (2004, p. 249): "A eleição de uma vida filosófica em oposição a uma vida não filosófica.

Assim, por exemplo, como esclarece Hadot (2004, p. 257) "na escola platônica o diálogo seria parte integrante do modo de vida filosófico, enquanto a escolha de vida aristotélica é 'viver segundo o Intelecto', isto é, encontrar o sentido de sua vida e seu prazer na investigação".

Do que se segue que a filosofia como modo de vida é uma escolha, uma deliberação racional que, ao eleger uma 
maneira de conduzir-se na existência, tem-se a conjugação entre pensamento e ação, crenças e conduta. Seria esta a proposta de transformação de si: a de conduzir-se na vida filosoficamente, ou seja, onde a dimensão teórica implica de forma absoluta na vida prática.

É nesta eleição de vida filosófica que ambiciona propor, à condução existencial de si mesmo, mediante o melhor uso da razão e do discurso (logos) sem jamais eximir-se da busca do bem, do justo e da verdade, que a filosofia se propõe como formadora de condutas, constituindo-se em si mesma, a sua tarefa educativa às individualidades.

Do exposto precedente, é possível inferir o quanto tornase primordial a questão do discurso filosófico, aliás, é neste sentido em que a filosofia sempre representa uma ruptura com os sofistas, pois estes articulam seus discursos com a aparência e não com a realidade ${ }^{4}$. Ou, em outros termos, enquanto os sofistas se preocupam em ensinar técnicas de persuasão e de produção de argumentos com vistas a escapar sempre de refutações, o filósofo relaciona o discurso com a questão do valor do discurso, ou seja, qual a relação existente entre pensamento, palavra e ação, e nisto está a associação direta entre discurso e verdade, teoria e prática, racionalidade e eticidade.

Por conseguinte, o ensino de filosofia para ser caracterizado como tal, não pode prescindir desta função essencialmente formadora e, por isso, educadora das individualidades que lhe são atingíveis pelo seu discurso. Nisto, portanto, há de se recusar uma dimensão puramente teórica e abstrata da filosofia.

Esta dimensão tornou-se tão forte que parece ser senso comum na sociedade e entre os alunos, sejam estes do 
ensino médio ou superior que identificam a filosofia como atividade que ou área que trata de questões insolúveis ou de temas que escapam a qualquer empiricidade, ou o que é ainda pior, concebem a filosofia como simples retórica em que tudo pode ser relativizado conforme crenças individuais e exclusivamente subjetivas.

Muito disto se deve, conforme apresenta Hadot (2006, p. 57), "a historiadores contemporâneos do pensamento antigo que em geral são prisioneiros de uma antiga concepção puramente teórica e abstrata da filosofia”. Para Hadot (idem, 57): "Seria graças a Nietzsche, Bérgson e ao existencialismo que a filosofia voltaria a se redescobrir de maneira consciente uma forma de viver e perceber o mundo, uma atitude concreta".

Nesta necessária simbiose entre o discurso teórico da filosofia e a praticidade ordinária da vida, enumeram-se três características fundamentais desta relação ${ }^{5}$, para em seguida, relaciona-las com o ensino de filosofia.

I. O discurso filosófico justifica teoricamente a escolha de vida.

II. O discurso é um meio privilegiado graças ao qual o filósofo pode agir sobre si mesmo e sobre os outros, pois, se ele é a expressão de uma opção existencial daquele que o sustenta, sempre tem, direta ou indiretamente, uma função formadora, educadora, psicagógica e terapêutica.

III. O discurso filosófico é uma das formas do exercício do modo de vida filosófico.

De forma genérica poder-se-ia deduzir a partir dos pontos acima enumerados, que a filosofia tem no discurso a expressão de si mesma. 
O primeiro ponto (I) destaca a função de justificação que a filosofia possui. Assim o discurso filosófico demonstra as razões de escolha do modo de vida. Há, portanto, o vínculo entre a teoria e a vida prática, as duas dimensões do theorein, como destaca Reale ${ }^{6}$.

Em sequência (II) trata-se da relação entre o discurso, manifestação do filósofo não somente como fruto de teorização, mas, enquanto expressão do próprio modo de viver. Neste processo o discurso atua sobre os outros, de diferentes formas, de formação, de educação, de condução (psicagógica) e terapêutica, de cuidado e conhecimento de si. Assim, tem-se o discurso externo e o discurso interno de elucidação de si mesmo sobre si mesmo.

O último ponto (III) realça a própria função discursiva como exercício, isto é, atividade que integra o modo de vida filosófico.

Relaciona-se, pois, estas cruciais características discursivas da filosofia antiga, a exporem o estreito vínculo da relação entre teoria e prática filosófica, mediante a perspectiva de ensino de filosofia, nesta perspectiva inovadora a luz dos postulados de Hadot ${ }^{7}$.

No trabalho docente pode parecer vaga abstração propor que a filosofia justifique a escolha do modo de viver (I). Porém, acredita-se ser possível sua realização. Por exemplo: é comum à nossa época diferente manifestações em relação ao que se pensa do mundo, ou como se compreende o mundo no qual vivamos.

Dentro de uma inevitável perspectiva sociocultural na qual todos estamos envolvidos, é possível pensar sobre o que é comum ou o que possa ser proposto como característica 
geral a compor certos comportamentos sociais e certas escolhas individuais. Pode-se sugerir, mediante a reflexão do que se impõe como modo de vida predominante pensar diferenciações a este modo de existência. Assim, quando se tem uma sociedade de consumo, com certos valores e tendências habituais a formarem certos costumes, pode-se sugerir questões, tais como: É possível haver outras escolhas que não as socialmente ou culturalmente predominantes? Existe a possibilidade de escolha? Até que ponto e em que medida somos determinados a certos comportamentos, hábitos e crenças pela influência da mídia? E do sistema econômico? E o modo de vida da família a qual se pertença, corresponde a minhas tendências ou gostos pessoais? E as inovações tecnológicas, até que ponto formam e determinam o que somos?

Evidente, pois, que destas problematizações surgem inúmeras outras, bem como, torna-se possível maneiras múltiplas de trabalhar conteúdos for mais de filosofia nas áreas que a compõem como estética, ética, política, epistemologia. Além de propiciar um amplo trabalho interdisciplinar com disciplinas como a literatura, a física, a história, a biologia e a sociologia.

O modo de vida, portanto, na procura de justificação filosófica, ou seja, em busca das razões que nos fazem aderir ou recusar tendências, crenças e comportamentos pode ser o ponto inicial a inúmeras possibilidades para o ensino e a aprendizagem da filosofia.

Em sequência ao que se encontra no segundo ponto (II), surgem outras tantas possibilidades de construção didática da filosofia. 
Seria falso negar que o professor de filosofia não possua em seu discurso traços específicos de certas teorizações. Afinal, o professor e o pesquisador profissional em filosofia também possuem seu conjunto de crenças, uma certa situação econômica e social, integra também uma comunidade, possui uma história.

Neste sentido, sempre há alguma influência das opções e do conhecimento teórico sobre o que se é. E isto em pontos, talvez de suma importância, no que vem a formar a identidade do professor como pessoa. Porém, todo professor honesto, saberá que a filosofia, embora tenha seus sistemas e principais filósofos a influenciarem toda a tradição filosófica, não pode querer propor um ensino dogmático e fechado em si mesmo, aos alunos que se encontrarem em processo formativo geral, seja na escola ou no curso de graduação.

Então, considera-se, mesmo que hipoteticamente, que não exista este dogmatismo filosófico professoral. Assim, o professor com esta imensa tradição filosófica de séculos de pensamento irá apresentar e problematizar o mais possível de acordo com uma perspectiva ampla de entendimento e compreensão, para que neste processo gradual de ensino e aprendizagem, os alunos de forma crítica e coerente gerem em si mesmos as condições de escolher àqueles grandes filósofos que mais se adequam a sua perspectiva, ao seu horizonte de mundo.

O professor que assim agir estará exercitando aquela condição psicagógica do discurso, a de conduzir os seus ouvintes a pensarem em si mesmos como agentes de escolha, como sujeitos históricos e morais que estão a todo instante, a cada dia, a cada hora, construindo certo caminho que somente é percorrido por aquele que o percorre. 
Esta dimensão de preparação à vida tão primordial aos filósofos antigos, precisa ser retomada pelos professores de filosofia, porque a filosofia trata da existência humana, é, portanto, imprescindível problematiza-la, para assim construir novas possibilidades de escolha quanto ao que se quer viver ao que se deseja ser.

Propõe-se que nesta possibilidade haverá mais espaço e racionalidade no uso do tempo para formar gerações mais conscientes de si, logo, mais conscientes também do outro que lhe comunga e compartilha a existência.

A preservação do meio ambiente natural, a busca de uma sociedade mais justa e pacífica, a escolha de melhores valores, serão escolhidos e cultivados de forma consciencial. Lograremos assim, vencer a insistente barbárie?

Se há alguma provável possibilidade, não haverá de ser outro o caminho que de uma formação realmente educadora. E isto pressupõe romper com pedagogias massificantes, pressupõe inaugurar certa dimensão de crise para instaurar novas ideias e crenças, novos costumes e valores que se coadunem à eticidade do modo de ser filosófico.

Quanto ao discurso como exercício do modo de vida filosófico (III) este se volta a formação do indivíduo sem jamais prescindir do comum, isto é, do espaço público de atuação política que modifica as massas. Mas este agir público e político não corresponde a política partidarista, a facções ideologicizantes. Ao contrário, o filósofo sugestiona, aconselha, legisla e, muitas vezes é o comum da política que o discurso da filosofia claramente se opõe.

Neste ponto tem-se a Sócrates como o modelo, ao que serviria a filosofia enquanto preocupada com o político, 
sem, no entanto, aderi-lo a si mesma. Porquanto a política não deve gerir a filosofia, mas o oposto se lhe apresenta como verdadeiro.

Neste caso, o de Sócrates, e a interface entre filosofia e política, assere Reale (2005, p. 405):

Sócrates [...] renunciou à política entendida como práxis militante cotidiana, mas compreendeu perfeitamente e proclamou que o seu filosofar constituía uma espécie de atividade superior, à medida que ela era formadora de consciências morais enquanto desvelava os verdadeiros valores.

Em Sócrates o discurso é dialógico, é mediante esta característica do filosofar que Sócrates desvela com o outro o que verdadeiramente tem valor ao homem e comunidade política. Porque claramente sabia na negação própria de seu próprio saber, que é conforme as nossas intenções e conforme os objetos de nossos desejos que as ações irão direcionar-se.

Há, pois, a clara intenção de educar a consciência, para que nesta, haja um saber que saiba sobretudo de si, porque é através deste autoconhecimento formado no discurso filosófico interior que é formado a eticidade da conduta e a racionalidade do pensamento.

Do que segue que o sentido de filosofia na antiguidade é sempre também comunitário, é atividade a ser realizada em comum, é exercício de pensamento direcionado a ação. A abstração, pois, da filosofia enquanto discurso teórico objetiva sempre a formação da eticidade do agir humano. 
Hadot nos fala de um princípio, expresso no termo grego symphilosophein, que o autor traduz por "filosofia em comum" e torna-se contributivo a compreensão dos argumentos precedentes.

O symphilosophein representa, Hadot (2009, p. 94), "аo contrário de nossos dias, o aspecto pessoal e comunitário da filosofia”.

Tal significado, expressa claramente aquela dupla dimensão do theorein grego. Assim, o modo de vida filosófico é sempre a expressão de uma dupla formação, teórica de um lado e moral de outro, nisto encontram-se as duas dimensões discursivas da filosofia antiga, conforme propõe Hadot, e aqui apresenta-se como essenciais ao ensino de filosofia.

A transformação de si é a formação pessoal consoante ao aprimoramento da própria condição humana, expressa, tanto na racionalidade do pensamento como na virtude da ação. Logo, toda a modificação pessoal é sempre abertura de mudança as sociedades as quais pertençamos.

Em suma, pode-se conceber como provável contribuição do modo de vida filosófico ao ensino de filosofia a formação educativa de consciências sabedoras de si mesmas que, nestas condições, propiciarão ao futuro gerações essencialmente éticas e, por esta condição mesma, cuidadoras de si mesmas e do meio natural e material a que pertençam.

E mais, ter-se-á educado para a autonomia do pensamento que escapa ao egoísmo, pois a raiz deste pensamento autônomo estará o princípio que todos somos uma individualidade sempre em comum porque nunca sozinhos ou nunca isolados na manifestação de si, pois é na integração política e pública de nós mesmos que 
encontramos o principal sentido da existência humana, o “Outro" que não é o "Eu” mesmo, mas tem si a identidade comum ao nos identificarmos, reciprocamente, como humanos.

\section{EXERCÍCIOS ESPIRITUAIS COMO FORMAÇÃO DE UMA EDUCAÇÃO CÍVICA E MORAL}

No último diálogo de Platão, Leis (643e-644a), tem-se claro a diferenciação que o filósofo apresenta entre uma formação técnica, direcionada ao exercício de uma profissão e, ao que o filósofo denomina educação.

[...] educação para a virtude, que vem desde a infância e nos desperta o anelo e o gosto de nos tornarmos cidadãos perfeitos, tão capazes de comandar como de obedecer [...] essa é a única modalidade de educação que tentamos definir, a única, segundo o meu modo de pensar, que merece ser assim denominada. A que tem por finalidade a aquisição de riquezas ou de qualquer modo de força ou habilidade que não leve em consideração a sabedoria e a justiça, é vulgar e nada nobre e não merece absolutamente o nome de educação.

É evidente a relação entre educar-se e tornar-se cidadão. Neste aspecto há duas virtudes consideradas indispensáveis, a sabedoria (sophía) e a justiça (diké). É claro pois, que o que se deve chamar de educação difere-se de instrução, e é neste sentido que o ensino puramente formal e procedimental não pode constituir-se como a única opção de ensino. 
Se somente assim o for, corre-se o risco de formar gerações desprovidas de senso de humanidade e de consciência cívica, e são exatamente estas as qualidades que modicam e aprimoram as sociedades, fundamentalmente, sociedades imensamente desiguais e injustas, no qual a sociedade brasileira acaba por servir de exemplo.

Todavia, esta questão não é apenas social, mas é também profundamente moral. Mas, antes de se tratar deste quesito, caro a educação filosófica, apresenta-se os seguintes argumentos.

É evidente que o que se denomina de ensino formal, base das relações entre professores, alunos e conteúdos a desenvolverem-se em escolas ou universidades, prevê o conhecimento de saberes específicos para a compreensão do mundo, do trabalho, da natureza, das relações econômicas e sociais na ampla complexidade que compõem a vida humana ao longo da História.

Quando se trabalha conteúdos de matemática, este estudo ambiciona não somente o saber indispensável desta área à vida humana, mas também, o desenvolvimento do raciocínio que predispõe e possibilita aprender o próprio saber matemático. Assim, tem-se uma dupla dimensão de ensino: a de instruir, ou seja, tornar o aprendiz capaz de calcular, fazer operações e utilizar-se de fórmulas para determinado fim, e, de outra parte, a dimensão que corresponde ao trabalho do próprio pensamento na aprendizagem da matemática.

É a este pensamento que pensa a si próprio na aprendizagem, seja da matemática ou em química que 
mais se vincula a educação. E por quê? Porque opera uma transformação no indivíduo. Quem aprende algo não retorna ao ponto inicial e, este aprendizado realmente pertencente ao indivíduo, também irá compor o que o indivíduo é.

Quando Platão postula que a educação é educação para a virtude, tem-se esta dimensão do ensino que ultrapassa a técnica para o desempenho de determinada função ou atividade humana. Platão pensa, portanto, é neste aprendizado que irá integrar o indivíduo durante toda a sua existência, expressando o que se é na conduta. Temse assim uma educação direcionada ao caráter, aquilo que transcende a técnica por ser o fundamento do próprio ser da pessoa. Este é o fim dos exercícios espirituais que integram a filosofia como modo de vida, por isso, são exercícios que verdadeiramente educam.

Se fosse-nos autorizado modificar os termos, a filosofia como modo de vida, carrega consigo uma profunda proposta de reforma de mentalidade cultural. A mentalidade cultural é dependente, do que historiadores chamam de tempo de longa duração, conceito historiográfico introduzido pelo historiador francês Fernand Braudel. Escreve Vainfas (1997, p.134): “à concepção de mentalidades, é concebida como estruturas de crenças e comportamentos que mudam muito lentamente, tendendo por vezes à inércia e à estagnação"8.

Do que segue que o modo de vida filosófico seria uma prática que ambiciona modificar certos caracteres predominantes a caracterizar, de forma geral, os indivíduos e as sociedades, em aspectos que predominam por muito tempo, longamente, nas culturas e civilizações. 
Para propiciar ou acelerar a modificação destes laços de mentalidade cultural, entram em cena os exercícios espirituais que Pierre Hadot (2009, p. 137) conceitua da seguinte forma: "Prática voluntária, pessoal destinada a operar uma transformação do indivíduo, uma transformação de si [...] Os exercícios espirituais se realizam no discurso interior que orientam a nossa ação".

É possível perceber a relação entre este discurso interior que transforma e o que Platão chamou de educação. Assim, os exercícios espirituais pertencem àquela dimensão do discurso filosófico que ambiciona a transformação/ configuração de novas maneiras de ser e de proceder.

Neste intuito, o resultado que se prevê é o da transformação moral. Logo, mediante os argumentos aqui apresentados, o indivíduo educado não se utilizará da instrução jurídica para obter benefícios pessoais, e nem fará como fim da instrução química, a produção de armas químicas ou de bombas.

Os exercícios espirituais em sua relação com a educação humana, são "práticas de si" que objetivam formar para a civilidade, para uma formação realmente humanística que demonstra conhecer a responsabilidade adquirida com o conhecimento. O que se quer alcançar com tal atividade é uma disposição, ou seja, formar uma tendência interna a princípios morais fundamentais 9 .

Passa-se a análise do seguinte exemplo de exercício espiritual ${ }^{10}$, conforme os preceitos do estoicismo romano ${ }^{11}$, na certeza de contribuir à reflexão conjunta a problemática do ensino de filosofia. 
Em todos os teus atos, ditos e pensamentos, procede como se houvesses de deixar a vida dentro de pouco. Desempenha cada ação de tua vida como se fosse a última isenta de toda leviandade. É da perfeição moral passar cada dia como se fosse o último, sem comoções, nem torpores, nem fingimento. Que a morte esteja diante de teus olhos a cada dia e jamais terás algum pensamento baixo ou algum desejo excessivo $^{12}$.

Esta exortação de Marco Aurélio revela o exercício espiritual platônico de filosofia como preparação para a morte ${ }^{13}$. No estoicismo, conforme Hadot (2004, p. 277), revela "um exercício de atenção a si mesmo e de vigilância”. E complementa (idem, p. 277): O pensamento da possibilidade da morte confere seu valor e sua gravidade em todo momento e em toda ação da vida".

A ideia de finitude existencial do homem, contribui, conforme a tradição estóica, ao aprimoramento moral. Deve-se preocupar e eleger como centro de nossas ideias e ações o que realmente importa a vida humana. Assim, o valor das ações encontra-se na virtude em que a própria ação pode manifestar e produzir. O telos da vida é vivela virtuosamente, procurando o justo, o bom, a verdade, e afastando-se das paixões que escravizam.

A ética antiga funciona como uma terapia do cuidado de si que almeja vencer as tendências internas que somente buscam satisfazer o indivíduo, quanto aos seus desejos, prazeres e ambições materiais.

Nota-se a proximidade, contra qualquer ideia de anacronismo, dos postulados estóicos e sua correlação a 
presente contemporaneidade, época manifesta do excesso e do culto egoístico de si. Portanto, o exercício espiritual que propõe pensar na brevidade da vida carrega consigo esta consciência moral da responsabilidade que se tem sobre o presente, sobre as ações praticadas e sobre o legado que será deixado há futuras gerações.

A profundidade desta reflexão filosófica contribui à formação educativa a todos que a ela se dispõem, e fogem do ensino procedimental promovido na maioria das instituições de ensino, presa ao formalismo e as regras determinantes e determinadoras de muitos postulados pedagógicos que somente objetivam instruir para servir ao mercado, mas não para educar para a autonomia, para a crítica e para a eticidade.

Os exercícios espirituais são múltiplos, pertencentes a muitas e diferentes escolas filosóficas da Antiguidade. Citamo-lo somente um exemplo, para servir a demonstração de que muito tem-se excluído do ensino de filosofia. Porquanto quer-se extrair desta, o profundo valor trazido de sua originalidade antiga que é o autoconhecimento, o exame de si, a consciência que devemos adquirir para ser possível, saber que é possível, pensar e almejar um mundo realmente melhor.

\section{NOVAS POSSIBILIDADES E ALGUNS VELHOS PROBLEMAS ${ }^{14}$}

Em entrevista à Revista Época (2016, p. 68-69), a Madre Montserrat del Pozo ${ }^{15}$, freira espanhola que recebeu a missão do Vaticano de investigar o que era feito de mais 
eficaz em educação do mundo, chega a algumas conclusões consideradas cruciais ao ponderar-se sobre a atividade de ensino e a educação. Reproduz-se aqui algumas de suas conclusões mais relevantes a investigação proposta.

$\mathrm{Na}$ seguinte pergunta: "Como se desenvolve o pensamento crítico do aluno?” Ao que responde a Madre (idem, p. 68): "É preciso uma mudança sistêmica no colégio, que vise instaurar a reflexão crítica em todo os níveis da escola, da gestão ao aluno. Para isso, existe uma série de protocolos. O resultado são instrumentos que transformam as aulas numa aula de pensamento".

A partir do referido argumento é possível asserir que "a aula pensamento" não se restringe a aulas de filosofia. $\mathrm{O}$ pensamento que pensa sobre si mesmo no ato de aprender é capaz de criar significados para o aprendizado realizado. Interliga-se conteúdo e prática, teoria e experiência ordinária.

Criar significados a si mesmo do aprendido gera sentido a aprendizagem tanto quanto ao ensino. Porque aprender é maior que ensinar no sentido de que o aprender é constitutivo a própria condição humana. Como postulava Aristóteles no início de sua Metafísica, A 1: “Todos os homens têm, por natureza, desejo de conhecer”.

Esta proposição de Aristóteles é fundamental. Porque se deve unir em sala de aula este princípio natural da natureza humana ao conhecimento, e associa-lo ao processo de aprendizagem. E como é possível fazer esta transposição entre teoria e prática? Crê-se que a hipótese proposta pela Madre é um caminho de excelência para tal fim. Mas, para isso, é necessário repensar a ocupação dos 
espaços oferecidos a cada disciplina do currículo escolar obrigatório, bem como, as avaliações a serem aplicadas.

Neste sentido não se pode querer uniformizar as aulas e as avaliações, sejam estas últimas, realizadas tendo em vista avaliações internas para que o aluno avance nos anos escolares ou em relação a avaliações externas que objetivam às universidades. Deve-se pensar, fundamentalmente no caso do ensino médio, o que este é ou deve ser em si mesmo, e não em relação a continuidade ou não dos estudos formais.

O mundo contemporâneo gerou uma mentalidade particularmente voltada a um único centro, que se constitui no que se chama "mercado". Neste sentido a própria educação se mercantilizou. O valor do indivíduo e da cidadania passou a ser o correspondente do lugar em que se ocupa nos meios de produção.

Sem dúvida, o sistema capitalista, a partir de sua formação nos séculos XI e XII e consequente consolidação e hegemonização nos séculos seguintes, trouxera avanço as sociedades, mas também propiciara a diminuição do valor indivíduo como pessoa em sua dignidade humana.

Em consequência, grande parcela da juventude cultiva e compartilha de certos hábitos, crenças e costumes que são meros resultantes da grande influência externa que recebem, a todo instante, em meios físicos e virtuais de grandes marcas, companhias e multinacionais e de corporações, anula-se, em grande medida, o indivíduo pensante que pense em outras possibilidades de ser em outros modos de vida. 
Existe uma certa força vinculada ao grande capital que teme e procura evitar aqueles que destoam do uniforme. E claro, nisto se inclui certas instituições e escolas teóricas que consideram prejudicial à educação para a autonomia e para a criticidade da cultura e do pensamento. Mas prejudicial a quem? Como bem pondera o professor e antropólogo Juvenal Arduini, (2002, p. 22):

Procura-se adaptar as pessoas às normas existentes e leva-las a reproduzir-se como cópias da situação predominante. Enquadra-se o rebanho humano no código uniformista. Impõe-se à população o paradigma oficial. Em quem diverge do 'consenso' é condenado como herege. Assim, o mundo continua a ser o mesmo, dominado pelos mesmos, usado pelos mesmos, usurpado pelos mesmos.

Neste sentido, não se pode exigir por exemplo, no tocante as avaliações, que as disciplinas tenham o mesmo propósito avaliativo ou, o que é ainda pior, tenham as suas avaliações marcadas no calendário de forma externa, isto é, com datas marcadas pela, comumente é assim realizado - nas salas de coordenação pedagógica - pois isto revela, no fundo, uma superficialidade no processo de ensino e aprendizagem, pois trata os conteúdos de maneira puramente formal e impossibilita grandemente "a aula pensamento", proposta pela Madre Montserrat e, da mesma forma, portanto, atividades que pensem o conhecimento no processo do aprender para a compreensão e atuação no mundo e na sociedade. 
O trabalho da Madre Montserrat (2016, p. 68) realizado por décadas, demonstra a seguinte conclusão geral: "Em escolas muito distintas, encontrou um problema comum: elas não formavam pessoas capazes de lidar com o mundo de forma autônoma. Aos adolescentes que saíam da escola, faltava capacidade de análise. Faltava autoestima e autoconhecimento".

Nestas ponderações, nota-se o quanto a proposta de Hadot em relação aos aspectos gerais e fundamentais que caracterizam a filosofia antiga podem contribuir ao ensino de filosofia e ao ensino em geral.

Primeiramente, a questão da autonomia ${ }^{16}$. A autonomia é um saber necessário para a vida prática e as relações humanas, sejam estas na família, entre amigos, ou nas relações sociais em geral. Ser autônomo significa saber conduzir-se na vida de maneira responsável e coerente.

Ao jovem, significa criar em si mesmo condições racionais, morais e emocionais para libertar-se sadiamente e, de forma gradual, aos que lhe são responsáveis, transferindo a responsabilidade do outro para si. Promovese assim a consequente maturidade adulta, e abstrai-se a dependência excessiva que parece prevalecer nas sociedades contemporâneas.

Quanto à questão da ausência de capacidade de análise referida pela Madre, considera-se que esta é dependente, desta falta que a Madre revela haver de autoestima e autoconhecimento. Pois, a dificuldade cognitiva para analisar objetos exteriores vincula-se a ausência do exercício de analisar a si próprio. 
Aquele que não é iniciado no autoconhecimento, isto é, no preceito socrático do exame de si, não cria condições de análise ao que se lhe apresenta como exterior a si mesmo. É esta ausência que se propõe a sanar na "aula pensamento". Porquanto, quando há o que poder-se-ia denominar-se de educação para o pensar cria-se condições de análise sobre si próprio e sobre objetos exteriores que se apresentem para análise, sejam estes pertencentes as aulas de química ou biologia, história ou literatura.

Neste intuito cria-se um "espaço comum" ao redor do conhecimento. Em consequência, o aprender não será automatizado como saber que visa sempre e somente a algum fim, seja este, a aprovação final no ano escolar ou ao êxito em exames esternos para a continuidade dos estudos em outro nível.

Considera-se que a dimensão discursiva da filosofia que almeja a transformação de si, cria, em sua prática de exercício espiritual, novas perspectivas e possibilidades quanto à escolha do modo de vida, reforça assim, a conquista da autonomia, do autoconhecimento e, em consequência, aumenta a autoestima porquanto possibilita ao sujeito conhecer-se a si mesmo e indagar-se quanto a coerência ou não de seu próprio conduzir existencial.

\section{CONCLUSÃO}

O artigo propôs demonstrar o quanto é possível pensar o ensino de filosofia como problema filosófico, a partir da utilização de conceitos cruciais que, embora 
não fossem pensados em sua originalidade ao ensino de filosofia, possibilitaram desenvolver novas perspectivas para problematizar a questão fundamental do ensinar e aprender filosofia.

Os estudos de Pierre Hadot sobre filosofia antiga fundamentam-se em dois princípios fundamentais como fora demonstrado: "a filosofia como modo de vida" e os "exercícios espirituais".

A partir deste viés interpretativo utilizou-se lhe de tais conceitos ou princípios, aos quais fundamentam o caráter comum da filosofia antiga, ao longo dos séculos que a cobrem, para se lhe utilizarem como possível caminho interpretativo às questões que envolvem o ensino e o aprendizado de filosofia.

Neste propósito, contribuiu-se a esta elaboração hermenêutica, servindo-se de alguns postulados sugeridos pela filósofa e Madre espanhola, Montserrat del Ponzo.

Como resultado da precedente elaboração deste artigo, algumas conclusões tornam-se possíveis, tais como:

O ensino de filosofia perpassa a atividade do filósofo desde suas origens históricas na Antiguidade grega. $\mathrm{O}$ filósofo antes mesmo de ser ou tornar-se um professor é um educador. Pois um dos objetos mais caros ao saber em que se ocupa tem na educação do homem e das sociedades uma expressão direta de seus propósitos e indagações.

Portanto, a filosofia, tal como existiu e fora praticada na Antiguidade, em suas principais dimensões discursivas que expressa o binômio grego de theorein pode e deve ser utilizado para o aprendizado e o ensino de filosofia. E isto em relação a diferentes conteúdos filosóficos. Porquanto o 
fundamento é um só: interpretar e compreender o mundo para tornar-se possível a sua transformação.

Contudo e, crê-se haver demonstrado, não há modificação nas sociedades, nos costumes e na mentalidade cultural sem, no entanto, haver previamente construído a transformação do homem em si mesmo.

E, esta transformação profunda no pensamento e no comportamento humano que almeja a eticidade nas relações, a autonomia e a criticidade, tornam-se possíveis na atividade constante de certos exercícios que, por sua vez, promovam o indispensável saber de si.

Indagar-se sobre qual o ensino e qual a educação que se deve construir é questionar-se sobre a própria vida humana, sobre os modos de existência que estão sendo praticados na vida pessoal e na vida coletiva na contemporaneidade de nosso tempo.

Acredita-se, com convicção, que a filosofia pode ainda mais contribuir à formação de condutas que reflitam o melhor do ser humano em cada individualidade humana. Afinal, como viver, sem indagar-se pelo sentido da própria vivência? Por que estudar se não haver o saber que indaga sobre o próprio aprender? Quais os motivos a tanto e variado conhecimento se as intenções são de sustentar a ignorância?

"Uma vida sem exame não é [será] digna de ser vivida ${ }^{17 "}$ 


\section{NOTAS}

${ }^{1}$ Doutor em Filosofia pela Pontifícia Universidade Católica do Rio Grande do Sul (PUC-RS). E-mail: gabiphilo78@gmail.com.

${ }^{2}$ Como bem pondera Reale (2005, p. 404): "Podemos, em suma, dizer que a constante da filosofia grega é o theorein, ora acentuado na sua valência especulativa, ora na sua valência moral, mas sempre de modo tal, que as duas valências se implicam reciprocamente de maneira estrutural [...] os gregos consideraram sempre como verdadeiro filósofo, apenas aquele que demonstrou saber realizar uma coerência de pensamento e de vida e, portanto, aquele que soube ser mestre não só de pensamento, mas também de vida." [Itálico no original].

${ }^{3}$ Sobre estas e outras habilidades e competências concernentes ao ensino e aprendizagem de filosofia, consultar Orientações Curriculares para o Ensino Médio: ciências humanas e suas tecnologias, v. 3, 2006. (pp 29-34). Mediante este documento governamental, produzido pelo Ministério da Educação (Secretaria de Educação Básica), revela-se o quanto a temática deste artigo pode ser inovadora e contribuidora a novas práticas de ensino de filosofia, sem excluir-se o que já se encontra oficialmente proposto.

${ }^{4}$ Como assere Aristóteles (165a 20): "Ora, para certa gente é mais proveitoso parecer que são sábios do que sê-lo realmente sem o parecer (pois a arte sofística é o simulacro da sabedoria sem a realidade, e o sofista é aquele que faz comércio de uma sabedoria aparente, mas irreal)".

${ }^{5}$ Em síntese ao apresentado por Pierre Hadot (2004, pp. 253-258).

${ }^{6}$ Consoante a nota 1 deste trabalho.

${ }^{7} \mathrm{O}$ próprio trabalho de desenvolvimento e argumentação desenvolvido para este artigo, é exemplo de atividade filosófica, isto é, de conceitos utilizados para a compreensão de determinada subárea da filosofia, reutiliza-se tais conceitos para servir de contribuição e reflexão a outra subárea filosófica. O trabalho de atualização e reutilização de conceitos, pois, integra a prática teórica da filosofia. Considera-se tal prática como útil à docência de filosofia, na medida em que contribui não somente a sua compreensão teórica, mas também a sua correlata efetivação prática.

${ }^{8}$ Afirma Ginzburg (1988, p. 16): "Insistindo nos elementos comuns, homogêneos, da mentalidade de um certo período, somos inevitavelmente induzidos a negligenciar as divergências e os contrastes entre as mentalidades das várias classes, dos vários grupos sociais, mergulhando tudo numa mentalidade coletiva indiferenciada e interclassista." 
${ }^{9}$ Assere Hadot (2009, p. 99): "As obras filosóficas da Antiguidade não se compõem para expor um sistema, senão para produzir um efeito de formação. Criar nos leitores e auditores uma disposição determinada. "

10"A palavra 'espiritual' permite compreender com maior facilidade que exercícios como estes são produto não somente do pensamento, mas também de uma totalidade psíquica do indivíduo que, em especial, revela o autêntico alcance de tais práticas: graças a elas o indivíduo ascende ao círculo do espírito objetivo, que significa que volta a situar-se na perspectiva do todo". (Hadot, 2006, p. 24).

${ }^{11}$ Conforme Hadot (2004, p.187): "A escola estóica, fundada por Zenão no fim do século IV a. C, ganha novo impulso por volta da metade do século III, sob a direção de Crisipo [...] O discurso filosófico estóico comporta três partes, a física, a lógica e a ética [...] É certo que, até o século II d.C., a doutrina estóica era ainda florescente no Império romano: basta citar Sêneca, Musônio, Epicteto e Marco Aurélio."

${ }^{12}$ Marco Aurélio, Meditações, II, 11; II, 5, 2; VII, 69. Citado em Hadot (2004, p. 277).

${ }^{13}$ Encontra-se no diálogo platônico Fédon (64a): "Os homens ignoram que os verdadeiros filósofos trabalham durante toda sua vida na preparação de sua morte."

${ }^{14}$ Neste subtema o objetivo é direcionar algumas reflexões para a prática docente. Toma-se como ponto de referência a própria experiência docente no magistério de educação básica do autor deste artigo.

${ }^{15}$ Madre Montserrat del Pozo é filósofa pela Universidade da Pensilvânia e mestre em psicologia pela Universidade de Massachusetts, ambas nos Estados Unidos.

${ }^{16}$ Para o professor e especialista em ensino de filosofia e filosofia da educação, Walter Omar Kohan (2009, p.70): "O ensino de filosofia - ou de maneira mais ampla, uma educação filosófica - exige autonomia por todas as partes: autonomia da própria filosofia diante de outros saberes e poderes, autonomia do professor ante os marcos institucionais que o regulam; autonomia de quem aprende ante a quem ensina e os outros aprendizes. As exigências de autonomia são diversas, múltiplas".

${ }^{17}$ Platão (38a). Entre colchete é acréscimo do autor deste artigo. 


\section{REFERÊNCIAS}

ARDUINI, J. Antropologia: ousar para reinventar a humanidade. 6. ed. São Paulo: Paulus, 2002.

ARISTÓTELES. Dos Argumentos Sofísticos. Tradução Leonel Vallandro e Gerd Bornheim. In: Os Pensadores. v. IV. São Paulo: Abril Cultural, 1973.

HADOT, P. La Filosofía como forma de vida: Conversaciones con Jeannie Carlier y Arnold I. Davidson. Traducción María Cucurella Miquel Barcelona: Ediciones Alpha Decay, 2009.

HADOT, P. Ejercicios espirituales y filosofía antigua. Prefácio de Arnold I. Davidson. Traducción Javier Palacio. Madrid: Ediciones Siruela, 2006.

HADOT, P. O que é a Filosofia Antiga? Tradução Dion Davi Macedo. 2. ed. São Paulo: Edições Loyola, 2004.

JAEGER, W. Paideia: A Formação do Homem Grego. Tradução Artur M. Parreira. São Paulo: Martins Fontes, 2003.

KOHAN, W. Filosofia: o paradoxo de aprender e ensinar. Tradução Ingrid Müller Xavier. Belo Horizonte: Autêntica Editora, 2009. (Coleção Ensino de Filosofia)

PLATÃO. Apologia de Sócrates, Críton, Laques, Cármides, Lísis, Eutífron, Protágoras, Górgias. In: Diálogos. Tradução Carlos Alberto Nunes. São Paulo: Edições Melhoramentos, 1970.

PLATÃO. Leis e Epínomis. Tradução Carlos Alberto Nunes. v. XII-XIII. Pará: Universidade Federal do Pará, 1980. 
POZO, M. A estabilidade do professor sabota a educação. [Entrevista concedida]. In: Revista Época. São Paulo, n. 930, 11 de abril, 2016. pp. 68-70.

REALE, G. História da filosofia antiga. Tradução Marcelo Perine. 5. ed. São Paulo: Edições Loyola, 2005. (Série História da Filosofia)

VAINFAS, R. História das Mentalidades e História Cultural. In: VAINFAS, R; CARDOSO, C. F (orgs). Domínios da História: ensaios de teoria e metodologia. Rio de Janeiro: Campus, 1997. 